$L$, but also on the mis-match reaching a certain value $m_{1}$ (Fig. 9). In this case ordinary catch-up would occur until the mis-match reached $m_{2}$, equal to $m_{1}$. As the scanty experimental and clinical data make it seem probable that in fact puberty occurs before the catch-up velocity has actually fallen the whole way to the usual preadolescent velocity, we may think that the relationships are quantitative, and that a further lowering of the tally velocity after $L$ is passed makes possible a higher mismatch, the combination of the two being the quantity required to reach a threshold value. A two-factor linkage such as this seems more typical of events in growth than a single-factor one, in that it permits greater variability among a number of individuals. In this sense it is a 'Iooser' coupling. Actually the recent results of McCance ${ }^{5}$ on starvation and re-feeding in pigs agrees with a fairly simple direct linkage; for puberty occurred in the starved and then fed pigs much before the body has caught up to its usual puberty size.

The model must be capable of explaining the disorder of precocious puberty. In some cases pubertal changes occur early, at a nearly normal size for chronological age; the children then finish their growth as very small adults. Essentially the same can be brought about in rats by destruction of an area in the hypothalamus; in an experiment of Donovan and Werff ten Bosch ${ }^{6}$ vaginal opening occurred at 33 days instead of 40, but the growth in size of body was not accelerated. In this case, we may suppose that $L$ has been drastically moved back along the tally curve, that is, that the linkage occurs at a higher tally velocity than normal. Physiologically, it may be that the inhibitory impulses to the pituitary are steadily diminishing as the velocity of the time tally diminishes (that is, as the maturity of the cells increases). If some of the inhibitory cells are destroyed, then the total effective inhibition diminishes, and the threshold is reached at an earlier point on the tally curve.

Other cases occur in which the child grows excessively fast from an early age, at first without any signs of puberty. He reaches puberty early, however - very early as regards chronological age and somewhat early as regards size. The growth regulation of such a child is represented in
Fig. 10. The simplest supposition is that the form of the tally curve is distorted so that its velocity is at first abnormally large. This would give rise to an abnormally large mis-match at the beginning of growth and hence to the accelerated growth. The point $L$ would occur early in chronological time, if it reflects the same critical velocity as usual in the time tally. In this form of precocious puberty therefore, puberty would occur early without any shift in time-tally threshold.

A striking example of experimentally produced disturbance of the regulatory mechanism has been given by the work of Kennedy, McCanee and Widdowson in rats ${ }^{7,8}$. Rats which are malnourished during the first 21 days following birth-which corresponds very approximately to the period from the fourth month of foetal life onwards in man-never catch up afterwards on their well-nourished litter-mates' curve, although they do show some catch-up growth on unrestricted feeding. When rats are starved at older ages catch-up does occur. In terms of the hypothesis presented here, the malnutrition occurring while the brain was still relatively rapidly growing apparently resulted in permanent damage to the time-tally mechanism. The hypothalamus seems the most likely location of the mechanism, particularly in view of the work of Harris and Jacobsohn', who showed that a new-born pituitary grafted into an adult hypophysectomized rat functioned as an adult pituitary as soon as vascular connexions were established. Thus information as to maturity is carried in the hypothalamus, or at some higher point in the brain.

${ }^{1}$ Prader, A., Tanner, J. M., and von Harnack, G. A., J. Pediat., 62, 646 (1963).

${ }^{2}$ Weiss, P., and Kavanau, J. L., J. Gen. Physiol., 41, 1 (1957).

"Tanner, J. M., "Growth and Constitution", in H uman Biology, by Harrison, G. A., Tanner, J. M., Weiner, J. S., and Barnicot, N. A. (Clarendon Press, Oxford, 1963).

'Bayer, L. M., and Bayley, N., Growth Diagnosis (Chicago Univ. Press, 1959).

5 McCance, R. A., Lancet, ii, 621, 671 (1962).

- Donovan, B. T., and Werff ten Bosch, J. J. ₹. d., J. Physiol., 147, 78 (1959).

7 Widdowson, E. M., and Kennedy, G. C., Proc. Roy. Soc., 156, B, 96 (1962).

' Widdowson, E. M., and McCance, R. A., Proc. Roy. Soc., 152, B, 188 (1960).

- Harris, G. W., and Levene, S., J. Physiol., 164, 17 (1962).

${ }^{10}$ Tanner, J. M., in Protein Metabolism, edit. by Gross, F. (Springer, Berlin, 1962).

\title{
IN THE SERVICE OF SCIENCE, INFORMATION AND THE ENJOYMENT OF LEISURE
}

T HE Lord Mayor of Oxford, in opening the Robert Maxwell Bookshop at Oxford housed in the Magdalen College Waynflete Building, described it as a bold enterprise and a most imaginative venture.

This new and most remarkably designed bookshop is also a cultural and information centre. Its $10,000 \mathrm{sq}$. ft. of space holds seven separate shops: including a general bookshop; a scientific, technical and medical bookshop; a paperback bookshop; a record and music shop; and finally, a stationery, office equipment and systems shop. In addition, there is an area designed for lectures, exhibitions and live recitals.

Service - not only to the people of Oxford but also to visitors in general -is the keynote of Maxwell's seven bookshops in one, planned carefully for more than three years. Its design and facilities incorporate the most modern American, British and Scandinavian techniques of displaying, recording and disseminating information of the printed and recorded word.

Students in Britain, elsewhere in the Commonwealth, and most other countries of the world will have the benefit of a new service in the supply of modern text-books, enabling them to acquire, under the Maxwell Budget Plan, all the books and other educational aids they need at the beginning of their full- or part-time studies and to pay for them by easy monthly instalments.

A unique, free bibliographical service for research workers and managers will help scientific research, industry and commerce to keep up to date with the latest professional publications throughout the world. Maxwell's free bibliographical service, based on co-operation with more than 1,000 of the most important publishers and institutions at home and abroad, brings users-on individual I.C.T. punch cards-accurate weekly advance information about all significant new publications on subjects of their own choice. The service is available in 435 subject classifications, ranging from medicine to packaging and marketing, to high-energy physics, plastics, building materials and teaching techniques.

A unique new feature of Maxwell's is the information systems, office equipment and stationery department. This will provide expert advice through its information and office-efficiency specialists-in consultation with each individual firm-on the best procedures, forms, facilities and equipment to be used to ensure the improvement or establishment of efficient and effective low-priced information systems, libraries and office methods in their firms. 


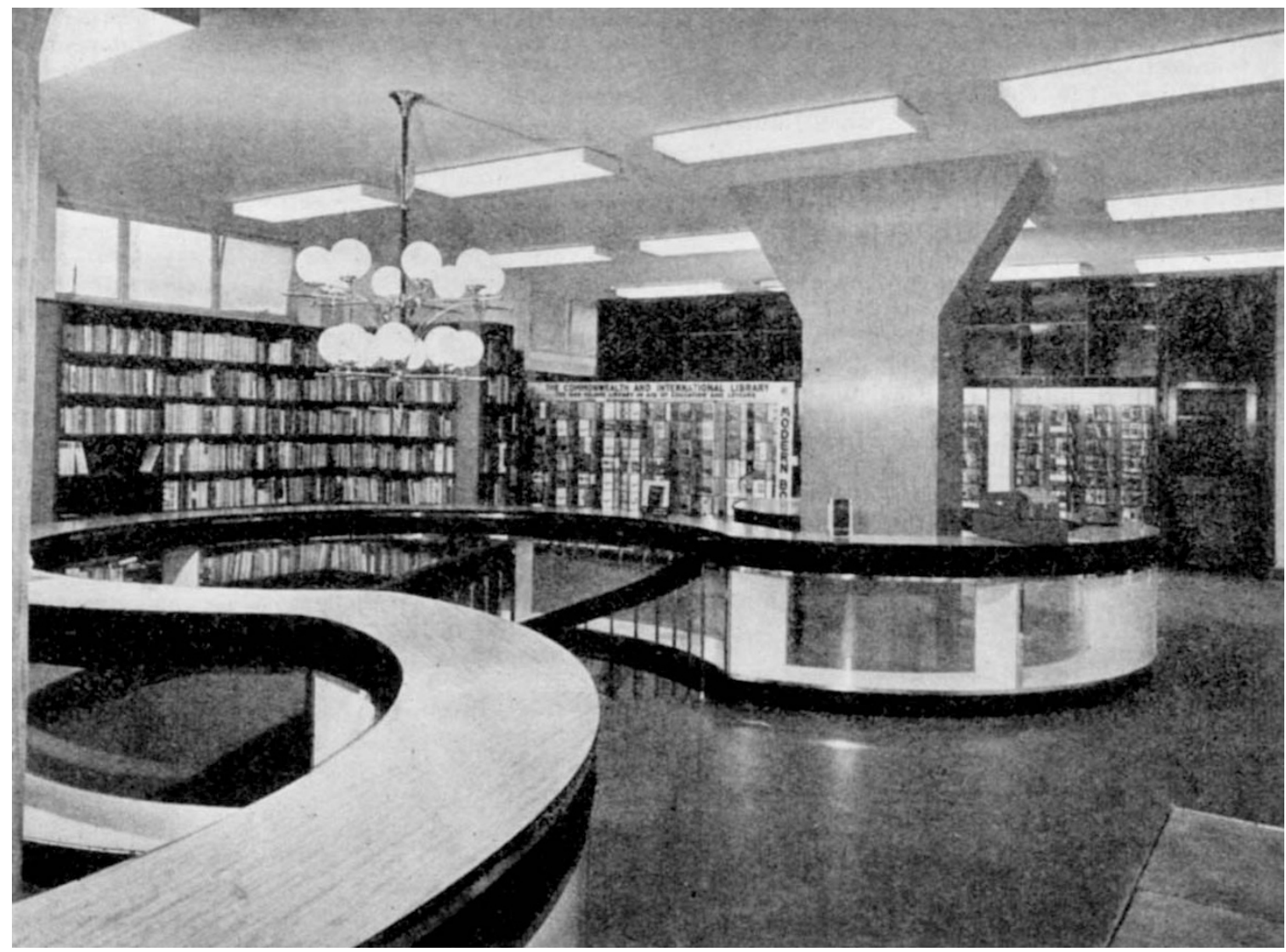

Fig. 1. Showcase and paperback book and journal section of the Maxwell bookshop in Magdalen College, Oxford

A further facility of interest to scientists is the stocking of a substantial range of scientific and medical books in German, French and Russian. There is also a "teachers and librarians only' room; in this room are displayed the latest text-books and terching aids.

Response from visitors from overseas suggests that Maxwell's will become the prototype of a chain of 'twentieth-century bookshops for university towns' all over the world. Following his recent tour of Maxwell's, for example, Dr. J. A. Matheson, vice-chancellor of the rapidly expanding Monash University, Victoria, Australia, invited Maxwell's to establish a bookshop on the University grounds at Clayton. A professor interested in plans for new buildings at Grenoble University has invited Maxwell's to participate. Long before these developments come to fruition, however, a second Maxwell's will be in operation in September opposite the University Medical Sehool in Edinburgh.

\section{OBITUARIES}

\section{Prof. Sidney Russ, C.B.E.}

Sidney Russ was born in London on December 2, 1879, and died on July 27, 1963. He started his career as a physicist in London, graduating from University College in 1905, after which he went to Manchester as demonstrator in physics. Here he spent five years in the exciting atmosphere of Rutherford's laboratories when new discoveries in radioactivity were almost a weekly occurrence. From this came his life-long interest in radioactivity, which led in 1910 to a most unusual step for a physicist to take. Having been awarded a Beit Memorial Fellowship, he docided to take it up in the new Cancer Research Laboratories of the Middlesex Hospital. This was followed in 1913 by his appointment as physicist to the Hospital, almost certainly the first appointment of its kind in the world and perhaps the starting point of a new branch of applied physics. In 1919 Russ transferred from Hospital to Medical School, and in 1920 was appointed to the newly instituted Joel chair of physics, which he held until his retirement in 1946.
During his early years at the Middlesex Hospital, Russ pioneered vigorously the application of precise physical principles and techniques to the use of radium and $X$-rays in medicine, a task for which his Manchester years well fitted him. Later his interests turned more to the biological and biophysical aspects of ionizing radiations, his greatest contribution probably lying in the field of radiation protection. His work with Gladys Scott on the biological effects of $\mathrm{X}$ - and gamma-rays at low doselevels, which seemed rather naive and crude at the time, was clearly pointing the way to the enormous range of investigations in this fiold carried out in recent years.

In 1919 there was growing concern about the hazards of the uncontrollod use of ionizing radiations. Russ became the first secretary of the British X-ray and Radium Protection Committeo, the first recommendations of which were published in 1920 . This slim document, produced before there was even an accepted unit of radiation dose, was quickly rocognized throughout the world and became the pattern for future codes of practice. In its style it clearly shows the imprint of the hand of Russ. 